\title{
II. ACTAS DEL II COLOQUIO BINACIONAL MÉXICO-ESPAÑA: DERECHO, JUSTICIA Y RAZONAMIENTO JURÍDICO
}

El Área de Filosofía del Derecho, a través del Prof. Dr. D. Juan Antonio García Amado, Catedrático de la disciplina, y el Grupo de Innovación Docente para la Enseñanza y el Aprendizaje del Derecho Civil, ambos de la Universidad de León (ULE), organizaron durante los días 14 a 18 de diciembre de 2015 el II Coloquio binacional México-España: Derecho, justicia y razonamiento jurídico.

A lo largo de estas Jornadas se sucedieron conferencias, debates, análisis e intercambio de experiencias entre los participantes a través de un formato que combinó 20 conferencias impartidas por investigadores seniors con 46 breves ponencias a cargo de jóvenes investigadores en Derecho; todo ello en intensas sesiones de trabajo estructuradas conforme al Programa que a continuación se recoge.

Es digna de destacar la diferente procedencia de los profesores implicados: no sólo de la Universidad de León, sino también de la Universidad de A Coruña, Universidad Internacional de Cataluña, Universidad de Málaga, Universidad del País Vasco, Universidad de Valencia, Universidad de Vigo y, por supuesto, de la Universidad Autónoma Nacional de México (UNAM).

Conste, para concluir, el agradecimiento de la organización a la UNAM y, en particular, al Prof. Dr. Carlos Humberto Reyes Díaz, Coordinador del Programa de Postgrado en Derecho de la UNAM, y a la Profra. Dra. Abril Uscanga Barradas. Sin la colaboración, hermandad y ganas de trabajar de ambos no hubiera sido posible la exitosa celebración del II Coloquio binacional México-España.

\section{Programa de actividades}

\begin{tabular}{|c|l|}
\hline \multicolumn{2}{|c|}{ LUNES 14 DE DICIEMBRE } \\
\hline 9:30 horas & ACTO DE APERTURA \\
\hline $\begin{array}{c}\text { 9:30-10:45 } \\
\text { horas }\end{array}$ & $\begin{array}{l}\text { CONFERENCIA "La crisis de los refugiados es el fracaso de la UE", Javier de } \\
\text { Lucas Martín. Catedrático de Filosofía del Derecho, Universidad de Valencia. } \\
\text { CONFERENCIA. "Exilio Republicano Español en México", Fernando Serrano } \\
\text { Migallón. Ex Director de la Facultad de Derecho y Profesor de la Universidad } \\
\text { Nacional Autónoma de México. }\end{array}$ \\
\hline $\begin{array}{c}\text { 11:00- } \\
\text { 13:20 horas }\end{array}$ & $\begin{array}{l}\text { RONDA DE PONENCIAS. } \\
\text { "Derechos Humanos de migrantes en tránsito por México, un asunto de } \\
\text { justicia pendiente. Idoneidad de las políticas públicas para su atención", } \\
\text { Curiel González, Ivón Elizabeth. } \\
\text { "Ensayo sobre una Teoría Crítica de los Derechos Humanos y algunos } \\
\text { contextos a discutir", Azar López, Bernardo Anwar. }\end{array}$ \\
\hline
\end{tabular}




\begin{tabular}{|c|c|}
\hline & $\begin{array}{l}\text { "El derecho a la seguridad como un paradigma de limitación de los derechos } \\
\text { fundamentales", Cervantes Velázquez Roxana Irene. } \\
\text { "Razonamiento jurídico en materia de Derechos Humanos", Castillo Sierra, } \\
\text { Bithia. } \\
\text { "La UE en la gestión de los flujos migratorios; una perspectiva comunitaria } \\
\text { para abordar el tema del derecho de asilo y de refugio", Bartholino, } \\
\text { Margherita }\end{array}$ \\
\hline $\begin{array}{c}13: 30- \\
14: 00 \text { horas }\end{array}$ & $\begin{array}{l}\text { CONFERENCIA. "Derechos Humanos, sociedades multiculturales y } \\
\text { conflictos", Ángeles Solanes Corella. Profesora Titular de Filosofía del } \\
\text { Derecho, Universidad de Valencia. }\end{array}$ \\
\hline \multicolumn{2}{|r|}{ Receso de actividades } \\
\hline $\begin{array}{c}16: 00- \\
17: 20 \text { horas }\end{array}$ & $\begin{array}{l}\text { CONFERENCIA. "El fracaso de la acción internacional en la protección de los } \\
\text { derechos humanos en el Mediterráneo", Consuelo Ramón Chornet } \\
\text { Catedrática de Derecho Internacional Público y Directora Instituto Derechos } \\
\text { Humanos, Universidad de Valencia. } \\
\text { CONFERENCIA. "Protección internacional de inversiones", Carlos Humberto } \\
\text { Reyes Díaz. Coordinador del Programa de Posgrado en Derecho y Profesor } \\
\text { de la Universidad Nacional Autónoma de México. }\end{array}$ \\
\hline $\begin{array}{c}17: 20- \\
19: 45 \text { horas }\end{array}$ & $\begin{array}{l}\text { RONDA DE PONENCIAS } \\
\text { "Retos del Sistema Jurídico en la protección ambiental", De los Santos } \\
\text { Martínez, David Humberto. } \\
\text { "Derecho, justicia y razonamiento jurídico en la libertad de tránsito vehicular } \\
\text { en el Distrito Federal", Flores Jiménez Elda Verónica. } \\
\text { "Los Derechos Humanos del contribuyente", Maldonado Villalpando, Irving } \\
\text { Alejandro. } \\
\text { "Los Derechos Humanos como límites al Derecho Fiscal Mexicano", Ramírez } \\
\text { Valle, Alejandro. } \\
\text { "Violencia institucional y estructural al servicio de un estado empresarial, en } \\
\text { busca de la injusticia social", Hernández Romero Oscar Omar. }\end{array}$ \\
\hline
\end{tabular}

\begin{tabular}{|c|l|}
\hline \multicolumn{2}{|c|}{ MARTES 15 DE DICIEMBRE } \\
\hline \multirow{2}{*}{$\begin{array}{c}\text { CONFERENCIA. "Transparencia Electoral", Cecilia del Carmen Azuara Arai, } \\
\text { 9:30-10:45 } \\
\text { horas }\end{array}$} & $\begin{array}{l}\text { Titular de la Unidad de Transparencia y Protección de Datos Personales del } \\
\text { Instituto Nacional Electoral y Profesora de la Universidad Nacional Autónoma } \\
\text { de México. } \\
\text { CONFERENCIA. "El Estado autoritario de gobernanza", Agustín J. } \\
\text { Menéndez Menéndez, Profesor (acr. Titular) de Filosofía del Derecho, } \\
\text { Universidad de León. }\end{array}$ \\
\hline
\end{tabular}




\begin{tabular}{|c|c|}
\hline $\begin{array}{c}11: 00- \\
13: 20 \text { horas }\end{array}$ & $\begin{array}{l}\text { RONDA DE PONENCIAS } \\
\text { "La libertad republicana como canal articulador de una sociedad igualitaria y } \\
\text { fraterna, sustentos básicos del Estado constitucional del siglo XXI", Osorio } \\
\text { Gómez, Octavio. } \\
\text { "¿Debemos insistir en pensar en la democracia?, Guerrero Navarro, } \\
\text { Salvador. } \\
\text { "Problemas y paradigmas de la relación entre: derecho, justicia y libertad", } \\
\text { Suenaga Olmeda, Iris Yanara. } \\
\text { "Problemas semánticos y de interpretación en el derecho: el caso de Estado } \\
\text { de Derecho", López González Francisco. } \\
\text { "La Teoría de distribución económica en México", Yudico Alcántara, Nancy } \\
\text { Paulina. } \\
\text { "Derecho de reunión y libertad de expresión a la luz de la actual orientación } \\
\text { político-criminal en España", Uribe Barrera, Juan Pablo. }\end{array}$ \\
\hline $\begin{array}{c}13: 30- \\
14: 00 \text { horas }\end{array}$ & $\begin{array}{l}\text { CONFERENCIA CONJUNTA. "El Neorepublicanismo como modelo de Estado } \\
\text { democrático: ¿Tiene futuro el republicanismo en México o España?", Abril } \\
\text { Uscanga Barradas, Profesora de la Universidad Nacional Autónoma de } \\
\text { México/ Juan Antonio García Amado, Universidad de León. }\end{array}$ \\
\hline \multicolumn{2}{|r|}{ Receso de actividades } \\
\hline $\begin{array}{c}\text { 16:00- } \\
\text { 17:20 horas }\end{array}$ & $\begin{array}{l}\text { CONFERENCIA "Acuerdos teóricos vs. Desacuerdos prácticos en la } \\
\text { interpretación judicial", Victoria Iturralde Sesma, Profesora Titular (acr. } \\
\text { Catedrática) de Filosofía del Derecho, Universidad del País Vasco. } \\
\text { CONFERENCIA. "Razonamiento Jurídico y Derecho Internacional Judicial", } \\
\text { Guillermo Enrique Estrada Adán, Profesor de la Universidad Nacional } \\
\text { Autónoma de México. }\end{array}$ \\
\hline $\begin{array}{c}17: 20- \\
\text { 19:30 horas }\end{array}$ & $\begin{array}{l}\text { RONDA DE PONENCIAS } \\
\text { "LOS derechos humanos como directivas de interpretación de las normas } \\
\text { jurídicas. Consideraciones críticas", Ríos Díaz, Sergio. } \\
\text { "¿El Derecho cambia? Una concepción entre derecho y justicia" Hernández } \\
\text { Lucas, Adrián. } \\
\text { "La producción "masiva" de leyes como obstáculo de la justicia. Panorama } \\
\text { hermenéutico", Aguirre Ponciano, Gustavo. } \\
\text { "La reivindicación de la abogacía a través de la ética: razones para la no } \\
\text { colegialización obligatoria", Fuentes González, Tanya Sarai. } \\
\text { "Nuevas fórmulas de contratación internacional de servicios turísticos: } \\
\text { especial atención a los dynamic packages", Carrizo Aguado, David. }\end{array}$ \\
\hline
\end{tabular}

\section{MIÉRCOLES 16 DE DICIEMBRE}

9:30-10:45

CONFERENCIA. "Prostitución y Derecho: el debate sobre el trabajo sexual", horas Concepción Gimeno Presa. Profesora Titular de Filosofía del Derecho, Universidad de León. 


\begin{tabular}{|c|c|}
\hline $\begin{array}{c}11: 00- \\
\text { 13:30 horas }\end{array}$ & $\begin{array}{l}\text { RONDA DE PONENCIAS } \\
\text { "Derecho y postmodernidad. Pensar, discutir, enseñar y aprender derecho con } \\
\text { nuevas categorías", Arellano Torres, Walter Martín. } \\
\text { "La impostergable inclusión del exceso ritual manifiesto, desde una } \\
\text { perspectiva argumentativa", Lechuga Xoconostle, Jessica Alicia. } \\
\text { "Los Modelos contemporáneos de justicia constitucional en el nuevo } \\
\text { paradigma de internacionalización de los derechos humanos", González } \\
\text { Porras, Lizette. } \\
\text { "Impartición de justicia para los empleados judiciales", Jiménez Carlos, Gabriel. } \\
\text { "Acceso a la justicia y razonamiento jurídico", Alcantar Valencia, Hugo } \\
\text { Andrés. } \\
\text { "La des-racionalización de la justicia en el sistema jurídico mexicano", Romo } \\
\text { Valdovinos, Iván Josué. }\end{array}$ \\
\hline $\begin{array}{c}\text { 13:30- } \\
\text { 14:00 horas }\end{array}$ & $\begin{array}{l}\text { CONFERENCIA. "El control del razonamiento presuntivo en sede de } \\
\text { recursos". Carlos de Miranda Vázquez, Profesor de Derecho Procesal, } \\
\text { Universidad Internacional de Cataluña. }\end{array}$ \\
\hline & Receso de actividades \\
\hline $\begin{array}{c}\text { 16:00- } \\
\text { 16:40 horas }\end{array}$ & $\begin{array}{l}\text { CONFERENCIA. "¿Es el especificacionismo una alternativa a la } \\
\text { ponderación?". José Manuel Cabra Apalategui, Profesor de Filosofía del } \\
\text { Derecho, Universidad de Málaga. }\end{array}$ \\
\hline $\begin{array}{c}\text { 17:00- } \\
\text { 19:30 horas }\end{array}$ & $\begin{array}{l}\text { RONDA DE PONENCIAS } \\
\text { "Inestabilidad de los agentes del ministerio público, peritos y miembros de las } \\
\text { instituciones policiales en el desempeño de sus funciones", Espinoza } \\
\text { Rodríguez, Juan Ignacio. } \\
\text { "La libre valoración de la prueba (Sistema Penal Acusatorio vigente en } \\
\text { México)", Muñoz Ortiz, Liliana. } \\
\text { "Justicia constitucional y su internacionalización", Roldán Orozco, Omar } \\
\text { Giovanni. } \\
\text { "Hacia la construcción y materialización de una justicia ambiental: caso } \\
\text { Colombia-México", Olaya López, Diego Felipe. } \\
\text { "Análisis del acceso a la justicia, presunción de inocencia, desde la } \\
\text { fundamentación kantiana en el proceso penal acusatorio y oral en México", } \\
\text { Rubio Suárez, Edith Alejandra. }\end{array}$ \\
\hline
\end{tabular}

\section{JUEVES 17 DE DICIEMBRE}

9:30-10:10

CONFERENCIA. "El parto anónimo". Marta Ordás Alonso, Profesora Titular horas de Derecho Civil y Directora del Departamento de Derecho Privado de la Universidad de León. 


\begin{tabular}{|c|c|}
\hline $\begin{array}{c}11: 00- \\
13: 20 \text { horas }\end{array}$ & $\begin{array}{l}\text { RONDA DE PONENCIAS } \\
\text { "El cambio de paradigma en el Derecho familiar mexicano. Un acercamiento al } \\
\text { razonamiento sociológico y jurídico del divorcio incausado frente al divorcio } \\
\text { causal", Alonso Ricárdez, José Manuel. } \\
\text { "Efectos en el Distrito Federal de la disolución de uniones de parejas del } \\
\text { mismo sexo con relación a los hijos. Guarda y custodia" Celis García, } \\
\text { Claudia. } \\
\text { "La desjudicialización de la Administración de Justica en un ámbito } \\
\text { "imposible": los procesos no dispositivos ", Llamas Bao, Cristina. } \\
\text { "El nuevo motivo del recurso de revisión para la ejecución de sentencias del } \\
\text { Tribunal Europeo de Derechos Humanos", Simarro Pedreira, Margarita. } \\
\text { "Instrumentos de protección ambiental en la UE y Brasil", Siqueira Loureiro, } \\
\text { Silvia Regina. }\end{array}$ \\
\hline $\begin{array}{c}13: 30- \\
14: 00 \text { horas }\end{array}$ & $\begin{array}{l}\text { CONFERENCIA. "Mecanismos alternativos frente al desahucio hipotecario". } \\
\text { Pilar Gutiérrez Santiago, Profesora Titular (acr. Catedrática) de Derecho } \\
\text { Civil, Universidad de León. }\end{array}$ \\
\hline \multicolumn{2}{|r|}{ Receso de actividades } \\
\hline $\begin{array}{c}16: 00- \\
16: 40 \text { horas }\end{array}$ & $\begin{array}{l}\text { CONFERENCIA. "¿Autoría mediata por utilización de aparatos organizados } \\
\text { de poder?". Miguel Díaz y García Conlledo, Catedrático de Derecho Penal y } \\
\text { Director del Departamento de Derecho Público de la Universidad de León, } \\
\text { España. }\end{array}$ \\
\hline $\begin{array}{c}17: 00- \\
\text { 19:30 horas }\end{array}$ & $\begin{array}{l}\text { RONDA DE PONENCIAS } \\
\text { "La ficha de identificación criminal en el Sistema Jurídico Mexicano", Rosas } \\
\text { García Francisco. } \\
\text { "Normas y antijuridicidad en Derecho penal", Alpaca Pérez, Alfredo. } \\
\text { "La justicia penal en épocas de transición", Serrano, Stephanía. } \\
\text { "Reforma penal, justicia y el nuevo Sistema Penitenciario en México", } \\
\text { Enríquez Hernández Salvador. } \\
\text { "Líneas maestras de la nueva contratación pública europea", Martínez } \\
\text { Fernández, José Manuel }\end{array}$ \\
\hline
\end{tabular}

\section{VIERNES 18 DE DICIEMBRE}

CONFERENCIA. "Sobre las diferencias conceptuales entre venganza y castigo". Pablo Bonorino Ramírez. Profesor Titular de Filosofía del Derecho,

9:30-10:45 Universidad de Vigo.

horas CONFERENCIA. "Medidas paliativas frente a la ejecución hipotecaria". Helena Díez García, Profesora Titular (acr. Catedrática) de Derecho Civil, Universidad de León. 


\begin{tabular}{|c|l|}
\hline & $\begin{array}{l}\text { RONDA DE PONENCIAS } \\
\text { "Los derechos laborales en México desde la perspectiva del trabajador } \\
\text { inmigrante: realidades y ficciones de un sistema normativo laboral } \\
\text { discriminatorio", Díez García, Javier. } \\
\text { "Los retos del sistema tributario ante las plataformas digitales de coche } \\
\text { 11:00- } \\
13: 20\end{array}$ \\
$\begin{array}{l}\text { compartido: el caso Blablacar", González Aparicio, Marta. } \\
\text { "Aspectos jurídico-tecnológicos de la movilidad por violencia de género de la } \\
\text { empleada pública", Gil Durán, María Paz. } \\
\text { "Supuestos y consecuencias de la violencia por omisión en el Estado } \\
\text { mexicano", Nussbaumer Ayala, José Carlos. }\end{array}$ \\
\hline $13: 30-$ & $\begin{array}{l}\text { CONFERENCIA. "La responsabilidad civil extracontractual como mecanismo } \\
\text { de protección de los derechos de crédito". José Manuel Busto Lago. } \\
\text { Catedrático de Derecho Civil y Decano de la Facultad de Derecho de la } \\
\text { Universidad de La Coruña. }\end{array}$ \\
\hline 14:00 horas & ACTO DE CLAUSURA \\
\hline
\end{tabular}

